\title{
PROSPECTIVA Y SUBDESARROLLO
}

\author{
JOSEPH HODARA * \\ Comisión Económica para América Latina
}

\begin{abstract}
"Nuestra era no es la primera que piensa poder predecir el futuro. Los griegos consultaban los oráculos; la Edad Media a los clérigos; el Racionalismo a los filósofos e historiadores. La única diferencia es que nosotros se lo pedimos a los científicos".
\end{abstract}

El PÁRRAFo que sirve de punto de arranque a estos apuntes sobre el estudio de problemas en un horizonte de largo plazo es instructivo por buen número de razones. Señala, en primer lugar, que la inclinación a explorar los futuros probables y posibles tiene amplios antecedentes: en segundo lugar, que dicha inclinación satisface necesidades psicosociales profundas, relacionadas bien con el ordenamiento temporal que toda sociedad requiere, bien con la simbología colectiva que respalda las acciones de los individuos;:- y el párrafo indica, en fin, que en el curso de la historia ha variado el carácter del consultado, mas no la tendencia a y la necesidad de la consulta.

El texto citado puede inducir, sin embargo, al error. Porque sin ignorar antecedentes pensamos que las condiciones en que se presentan en la actualidad los planteamientos de largo alcance son singulares, de modo que se vislumbran discontinuidades entre los ejercicios de hoy y las especulaciones de ayer.

En este ensayo se pondrá el acento en tres temas interrelacionados: i) algunos determinantes de la reflexión prospectiva tal como se viene articulando en los grandes centros industriales; ii) las áreas que han merecido atención; iii) los problemas particulares que se plantean al ejercicio prospectivo en un contexto de subdesarrollo, particularmente en América Latina.

* El autor agradece a los miembros del Grupo de Estudios sobre Prospectiva. auspiciado por El Colegio de México y el Instituto Nacional de Comercio Exterior. las observaciones críticas hechas a algunos capítulos de este trabajo y, en particular, a Víctor L. Urquidi. La responsabilidad por los juicios aquí emitidos es personal.

R. Heilbroner, Entre capitalismo y socialismo, Madrid, Alianza Editorial, 1972. p. 239.

"Estos anticipos del futuro pueden traducirse en expresiones de "catarsis social" Véase Y. Dror, "A Policy Science View of Future Studies", Technological Forecasting: and Social Change, Vol. 2, 1970. 
Huelga decir que no se pretende abrazar todos los aspectos del tema. Trátase apenas de una exploración preliminar, auxiliada por la amplia literatura que se viene acumulando sobre estos asuntos. ${ }^{3}$

\section{Determinantes de La ReFleXión PROSPECTIVA}

No es fácil identificar las circunstancias que han contribuido a difundir e institucionalizar — particularmente en las sociedades avanzadas- la indagación futurológica. Distinguiremos tres tipos de factores: $a$ ) macrosociales; $b$ ) político-organizacionales; $c$ ) profesionales.

a) La complejidad creciente de los procesos económicos y sociales -inducida por el crecimiento y la diferenciación de las sociedades modernas- enriquece, por una parte, el espectro de alternativas que el futuro proyecta hacia el presente; por otra, dificulta grandemente la toma de decisiones de interés colectivo. Estas dificultades emanan de dos circunstancias al parecer contradictorias: del exceso de información (o de "ruidos") que gravita sobre la formulación de decisiones, y de la insuficiencia de información respecto a las implicaciones mediatas (o de segundo orden) de una decisión ya asumida. Una y otra son resultado de la complejidad anotada que, en el plano de un presente determinado, se traduce en una multiplicidad de circunstancias y datos que deben tomarse en consideración; en el plano del futuro, multiplica las incertidumbres. ${ }^{4}$

En esta interacción entre complejidad estructural y decisiones colectivas pesan otros dos elementos: el ritmo acelerado de los cambios sociales y la importancia cardinal "de lo que está en juego". Que sociedades e individuos están hoy sujetos a transformaciones radicales que ponen a prueba la capacidad física y psicológica de adaptación es una observación frecuente. Las posibilidades de "encapsularse" son extremadamente reducidas. Ni los sistemas preindustriales, ni aquéllos en los que se efectúa un vasto experimento de reconstrucción social, se eximen de esta contaminación física y social mutua. El carácter comprensivo y ágil del cambio societal dota al futuro de dos atributos: inevitabilidad y concreción. Vale decir, el futuro se presentará necesariamente. La disyuntiva no es cambio o estancamiento, sino el estilo del cambio preferible o posible. Más aún: el futuro no está vacío: es un conjunto de sucesos que habrá de articularse o desplomarse sobre una situación determinada.

Y hay algo más. Si la indiferencia por el futuro se tradujera sólo en "errores administrativos" de limitada repercusión y de interés sólo para historiadores - si es que éstos llegan a enterarse-, podría justificarse la predilección por los problemas de hoy y de aquí. Pero no es el caso. Como se verá, en la viabilidad física de la especie humana -o al menos

3 Una buena selección de trabajos puede encontrarse en: A. Toffler (Comp.), The Futurists, Nueva York, Random House, 1972, y F. Tugwell (Comp.), Search for Alternatives, Cambridge, Mass., Winthrop Publishers Inc., 1973.

* Algunas ramificaciones de este asunto son estudiadas por O. Helmer y N. Resher, "On the Epistemology of the Inexact Sciences", en F. Tugwell, op. cit. 
la de los países subdesarrollados- lo que está en juego. Trátase de una confrontación total -ideológica, comercial y política - que ya se vislumbra en la presente coyuntura internacional. ${ }^{5}$ Hay lugar todavía para "errores administrativos"; pero el espacio no es muy amplio. De aquí que el futuro sea hoy demasiado importante como para dejarlo en manos del accidente o la contemplación.

Recapitulando: el sistema internacional contemporáneo presenta características singulares - complejidad, interdependencia y discontinuidadesque han condicionado la institucionalización del examen proyectivo de un conjunto muy amplio de problemas. Como en otros campos, son los países industriales los que han hecho avances rápidos en la materia, mediante la creación de una infraestructura institucional especializada. ${ }^{6}$ Más adelante veremos qué puede fluir de esta situación que entraña el estudio profundo pero unilateral de problemas universales.

b) Entre los factores político-organizacionales que han contribuido a difundir el interés por la prospectiva señalaremos la institucionalización de la planificación, el ascenso de entidades multinacionales, y la politización amplia del esquema internacional.

No abordaremos aquí los orígenes, las modalidades o los beneficios de la planificación. ${ }^{\top}$ Aquí interesan dos tesis: que la mayoría de los países - particularmente los económicamente avanzados- han puesto en marcha mecanismos de orientación y programación tanto en el plano de la política macroeconómica como en el interior de las unidades productivas y sociales; ${ }^{8}$ que el manejo de estos mecanismos ha difundido una actitud activa frente al tiempo, esto es, la convicción de que es posible y deseable intervenir y aún modelar los procesos socioeconómicos, en función de un conjunto de valores que conforman el marco estratégico de la planificación.

Cabe hacer algunas reservas. El reconocimiento público de la planificación y su grado de eficiencia varian apreciablemente entre los países. ${ }^{9}$ Se advierte, sin embargo, una tendencia creciente a adoptar estos mecanismos públicos de orientación e intervención en correspondencia a los

${ }^{5}$ Al pasar revista a los "desafios externos" a que se enfrentan los sistemas industriales, Heilbroner menciona el rápido crecimiento demográfico de los países subdesarrollados, el probable agotamiento de algunos recursos estratégicos, y la creciente aptitud militar de los subdesarrollados que podrían instrumentalizarse a fin de forzar una transferencia masiva de recursos. Véase R. Heilbroner, The Human Prospect, Nueva York, W. W. Norton and Co., 1974, cap. II.

- Sobre algunos datos al respecto véase P. Dickson, Think Tanks, Nueva York, Ballantine Books, 1971.

${ }_{7}$ El lector interesado encontrará nuevos elementos de juicio sobre este tópico en los trabajos de J. Sheahan y de R. E. Pahl-J. T. Winkler, publicados en Challenge, marzo-abril de 1975.

8 Obviamente, no sólo las empresas tratan de identificar y ponderar cursos alter. nativos de acción; también los hospitales, las universidades y otras organizaciones modernas.

- Esquemáticamente podremos distinguir cuatro situaciones: 1) países en los que la planificación tiene legitimidad ideológica y es razonablemente eficaz (las economías socialistas avanzadas y, tal vez, Francia, entre otros); 2) países en los que el 
grados de desarrollo y al papel central que hoy protagoniza el Estado, independientemente de las ideologías declaradas.

Una segunda reserva alude a las diferencias que deben establecerse, en cualquier caso, entre la planificación y la prospectiva, "1" tópico que será examinado en otro trabajo del autor. Pero estas diferencias no cancelan la validez de nuestra afirmación: la planificación ha acentuado la sensibilidad por las relaciones dialécticas que se crean entre la información, la decisión y el tiempo. Este último - cabe insistir- ya no es mirado como una entidad neutra o simplemente como una categoría gnoseológica que ordena los datos empíricos. Es más que eso: un factor tan significativo como las variables económicas y ambientales que decisiones colectivas suelen tener presentes.

El ascenso y la propagación de entidades multinacionales constituyen un fenómeno que, por un lado, acentúa las tendencias hacia la planificación ${ }^{11} \mathrm{y}$, por otro, propicia la politización del sistema internacional. ${ }^{1:}$ Ambos aspectos convergen en una preocupación: cómo asegurar el crecimiento sostenido - de la corporación en un contexto externo no especulativo, ni mercantilista - en donde se alternan componentes de suspicacia y hostilidad. Constituyendo las trasnacionales uno de los arquetipos más sobresalientes de la "modernización económica", no puéden menos que procurar el examen ordenado de tendencias y datos que podrían afectar su funcionamiento y flexibilidad. No debe sorprender, entonces, que, aparte de los gobiernos, un buen número de trasnacionales cuente ya con grupos especializados en estudios del futuro, al menos del futuro que consideran significativo.

La politización del sistema internacional propicia, en unión de los factores señalados, la inquietud por lo que envuelve el futuro. El tema es complejo. Intervienen aquí circunstancias históricas vinculadas con la descolonización, con la proyección de la "Revolución Inglesa" en los países de menor ingreso, ${ }^{13}$ con el acentuamiento de las desigualdades económi-

\footnotetext{
"discurso público" le niega legitimidad, pero en donde mecanismos de planificación operan con apreciable éxito (Estados Unidos); 3) países que adhieren ideológicamen. te a la planificación, pero que no han logrado su operacionalización efectiva (la mayoría en América Latina); 4) y, en fin, naciones nuevas que no han asumido compromisos en este campo.

- Al respecto véase B. de Jouvenel, The Art of Conjecture, Londres, Weidenfeld and Nicolson, 1967, y J. Friedman. "A Conceptual Model for the Analysis of Planning Behaviour", Administrative Science Quarterly, Vol. 12, septiembre de 1967.

${ }^{11}$ Aludimos aquí a las difundidas ideas de J.K. Galbraith, expuestas en su The New Industrial State.

$\because$ La literatura sobre el tema es abundante. Véase, por ejemplo. L. Turner. Multinational Companies and the Third World, Nueva York. Hill and Wang. 1973: y Naciones Unidas, Las corporaciones multinacionales en el desarollo mundial, Nueva York, 1973.

": Aquí aludimos a la tesis -interesante, por cierto-- de D.P. Moynihan, que pretende explicar la insurgencia de los países del llamado Tercer Mundo en las Naciones Unidas y foros internacionales. Véase su ensayo "The United States in Opposition", Commentary, marzo de 1975, y las reacciones que provocara en la
} 
cas, con la multipolarización política, $y$, en fin, con el desenvolvimiento de los organismos internacionales. De aquí resulta un lenguaje $-y$ variadas acciones- de confrontación internacional que tiene incidencias inmediatas $^{14}$ y de largo plazo. La situación inquieta a los grandes centros industriales, y no es para menos: la politización puede inducir a un peligroso juego de amenazas y contramenazas —expropiación de compañías que surten de recursos estratégicos a los países industriales, denuncia de la deuda externa, cierre de vías marítimas internacionales, guerra comercial, uso de los alimentos con fines políticos, y hasta el "chantaje químico" (biológico o atómico). ${ }^{n} \mathrm{De}$ aquí el acentuado interés en la formulación de diagnósticos globales con una perspectiva de largo plazo (piénsese en las iniciativas del Club de Roma), a fin de encontrar salidas humanistas a los dilemas del presente. Pero también se visualizan otras tendencias que oscilan entre la percepción unilateral de los problemas mundiales y el más fiero darwinismo ecológico. " Se produce, en cualquier caso, un interés renovado - que se sostiene en refinadas bases técnicas y metodológicas - en las indagaciones del futuro.

c) Considerados algunos determinantes macrosociales y políticos que crean la demandá por los estudios de prospectiva, veamos qué ha sucedido por el lado de la oferta. Dos fenómenos merecen examen desde este ángulo: la diferenciación profesional y la desideologización.

Es sabido que las diciplinas científicos han tendido a diferenciarse a través del tiempo en respuesta a la explosión informativa y factores conexos. ${ }^{17}$ La diferenciación no se ha contrapuesto necesariamente a la confluencia de disciplinas; pero de ésta ha surgido una rama más especializada (la biónica o la ingeniería médica, por ejemplo). Y bien: los estudios sobre prospectiva son apoyados también por un encuentro cruzado de disciplinas (matemáticas, ecología, economía, sociología, etc.) que pretende cultivar una percepción sistemática de los problemas huma. nos en un horizonte temporal de veinte años o más, con base en informaciones tácitas (no factuales). Esta nueva disciplina brinda - como cualquier otra - compensaciones psicológicas y estéticas profundas al paso que su utilidad social se amplía al calor del contexto descrito más arriba. El encuentro entre oferta y demanda se concierta en el marco de

inteligentsia norteamericana en Commentary, julio de 1975. Véase también la entrega de Time. 8 de septiembre de 1975.

"Algunas de éstas han sido abordadas por el autor en su trabajo "La coyuntu a internacional: cuatro visiones", Estudios Internacionales, Buenos Aires, Núm. 31. julio-septiembre de 1975.

15 Algunas de estas posibilidades han sido analizadas por G. Barraclough. "The World Economic Struggle". The New York Review of Books, agosto 7. 1975.

in Los fundamentos ideológicos de este nuevo tipo de darwinismo son abordados por el New York Time Magazine, enero 5, 1975.

"Por ejemplo, la productividad y el reconocimiento internacional del hombre de ciencia dependen en buena medida de una cuidadosa delimitación del área de especialización, hecha en los primeros años de trabajo profesional. Al respecto véanse los estudios de R.K. Merton. The Sociology of Science, Chicago. The University of Chicago Press. 1973. sección IV. 
gobiernos, universidades y empresas que dotan a la disciplina de la infraestructura y la respetabilidad académica necesarias.

La desideologización - sesgundo elemento que gravita en la ofertaes un proceso complejo, y generalmente mal comprendido, en América Latina en particular. ${ }^{18}$ Es obvio que esquemas ideológicos -como los valores en general - norman buena parte de nuestra conducta. Pero se pueden establecer diferencias en cuanto al grado de explicitación de los esquemas, de coherencia interna y externa, y de subordinación del comportamiento a los valores. ${ }^{13} \mathrm{Y}$ bien: nuestra tesis es que en ciertas sociedades industriales se han creado condiciones para que grupos selectos de profesionales expliciten con amplitud sus valores, obtengan grados apreciables de coherencia, y disciplinen en circunstancias señaladas el peso de los valores en la conducta. ${ }^{20} \mathrm{Y}$ la segunda tesis: la indagación del futuro entraña angustias y pasiones en el plano individual y, en el colectivo, propicia la visualización y acaso la puja de intereses encontrados. Los esquemas ideológicos aceptados son puestos así en tensión, y entonces se presenta gravemente el problema del "control" de la ideología. Si se carece de éste, difícilmente se podría ponderar y "jugar" con los futuros. En este sentido la relación psicoanalítica médico-paciente reviste analogías interesantes.

En suma: la exploración futurológica se apoya no sólo en la demanda social que se ha presentado en los países industriales por este tipo de estudios; es estimulada también por una diferenciación más avanzada de las profesiones que se traduce, en este caso, en la confluencia de varias disciplinas y en una actitud más depurada respecto del problema de los valores.

\section{LAS ÁREAS TEMÁticas}

Considerados algunos de los factores que han determinado -0 al menos afectado- el florecimiento de los estudios de prospectiva procedemos ahora a pasar revista a los temas que han atraído preferentemente la atención de los mismos. Como nuestro principal interés es contrastar las condiciones y tendencias de esos estudios con la situación de subdesarrollo

${ }^{18}$ Hemos tratado de dilucidar aspectos de esta controvertida cuestión en "La explotación de la sociología", América Latina: ¿El fin de los inrelectuales?, Lima, Universidad Villarreal, 1972

${ }_{19}$ Un interesante ejercicio en esta dirección lo practicó L. Solís en relación a los esquemas ideológicos de los economistas mexicanos. Véase L. Solís, "Mexican Economic Policies in the Post-War Period," The American Economic Review, junio de 1971.

${ }^{30}$ No son criaturas "fáusticas". En cierta medida, se ajustan a modelos conductuales preferidos por algunas corrientes psicoanalíticas y sociológicas. Véase al respecto J. Hodara, "Mannheim y Freud: una comparación sistemática", Revista Mexicana de Ciencias Politicas, abril-junio de 1968. 
haremos énfasis en aquellos asuntos que permitan trazar relaciones entre un tema y otro. Y aún así, el repaso será limitado.

Veamos: los límites físicos del crecimiento; las desigualdades internacionales; la reestructuración del orden mundial; y la transmutación de los valores.

\section{a) Los limites fisicos del crecimiento}

En los años recientes se ha acentuado la inquietud por el carácter presumiblemente finito y cerrado del sistema mundial que contrasta con las tendencias exponenciales del crecimiento económico y, en particular, con las del aprovechamiento de recursos físiscos. La difusión de los dos informes del Club de Roma hizo aún más intensa esta inquietud al indicar, entre otras cosas, que los patrones de funcionamiento de la sociedad industrial presentan señales de inviabilidad estructural. Esta afirmación contradice las siguientes premisas sobre las cuales ha descansado el crecimiento acelerado de los grandes núcleos industriales: $i)$ que los insumos requeridos por la actividad productiva y el consumo no reconocen restricciones significativas; $i i)$ que el abastecimiento de los mismos estaría asegurado por los mecanismos convencionales del comercio internacional; iii) que si $i$ ) y ii) no se cumplieran plenamente, las dificultades serían removidas en cualquier caso, bien por innovaciones tecnológicas (sucedáneos), bien por desplazamientos de las curvas de oferta y demanda (variación de precios y usos), bien por el ejercicio de "presiones extraeconómicas" (militares y políticas), o por la combinación de estos medios.

Varias circunstancias están llevando a la revisión de estas premisas. Nos ceñiremos a las de orden económico. ${ }^{21}$ Una de ellas se refiere a la confección de inventarios y diagnósticos en torno a los recursos y reservas disponibles. Bajo ciertos supuestos de crecimiento del consumo y progreso técnico, estos estudios pusieron en duda la posisbilidad de mantener en el largo plazo las pautas de desarrollo económico de las sociedades adelantadas. Por ejemplo, un informe reciente ${ }^{22}$ de este género indica que Estados Unidos alberga el $6 \%$ de la población mundial, pero consume el $31 \%$ de la oferta total de minerales. Y a pesar de que el país citado produce más de la cuarta parte del abastecimiento mundial de minerales - con sólo 7\% de la superficie terrestre- ya padece insuficiencias de insumos

${ }^{21}$ Hay otros de igual importancia: los impactos ambientales negativos del crecimiento y los grupos de presión que se han creado en torno a este asunto; la revisión fundamental que se está efectuando en varios centros académicos (en Estados Unidos e Inglaterra principalmente) de los supuestos, aseveraciones y resultados de la economía neoclásica, y la insurgencia de los países subdesarrollados que tiende a sustraer legitimidad a patrones de crecimiento sustentados en la explotación colonial.

Véase J. E. Mckelvey, World Resources, Reserves and U.S. Policy, informe presentado al NAS-NAE Symposium on National Materials Policy, Washington, D. C., 25 de octubre de 1973. 
importantes, como aluminio, níquel, cromo, bauxita, manganeso, tungsteno, cobalto y uranio.

Estas preocupaciones cobran notoriedad al advertirse la abrupta elevación de precios de los minerales y, en particular, del petróleo, hecho que refleja en parte el fortalecimiento de la capacidad negociadora de los productores de materias primas, y, en parte, la tendencia a desplazar el mercado de insumos básicos a nuevos puntos de equilibrio, a fin de estimular la búsqueda y explotación de fuentes descartadas en el presente.

Cabe observar, por otra parte, que aún aceptándose la posibilidad de acicatear el avance técnico a un ritmo sin precedente, esto demandaría alteraciones sustanciales en la asignación de recursos y en los usos alternativos de tierras y mares, con efectos colaterales en la distribución internacional del poder $\mathrm{y}$, en general, en los costos del desarrollo. ${ }^{23}$ Las restricciones, en suma, emanarían de otras fuentes, sin modificar el imperativo de transitar hacia un nuevo tipo ce economía - "a spaceman economy", diría Boulding - $2+$ que ponga en relieve la incidencia de diversas restricciones.

Adviértase que estos planteamientos sobre los límites físicos del crecimiento han sido y son cuestionados desde diferentes ángulos. ${ }^{25}$ Representan, sin embargo, un tema de la exploración prospectiva por las múltiples ramificaciones -demográficas, ecológicas, políticas- que presenta.

\section{b) Las desigualdades económicas}

Hay bases para suponer que las disparidades internacionales, regionales y nacionales en términos de ingreso, consumo y servicios tienden a ampliarse con el tiempo. ${ }^{26}$ El fenómeno plantea graves interrogantes. ¿Cuáles son sus causas?, ¿en qué consisten las insuficiencias de teorías y políticas que han pretendido remediar el problema?, ies la desigualdad un rasgo transitorio? Si no lo es, ¿cómo habrá de afectar la convivencia internacional?

Estas preguntas constituyen el meollo de varios intentos de análisis prospectivo efectuados recientemente. ${ }^{2 \tau} \mathrm{Y}$ no debe extrañar. La brechaingreso ya no es percibida como un hecho aislado, del que cada país de-

* Véase D. Brooks-P. W. Andrews, World Population and Mineral Resources: Counter-intuitive or Not?, U.N. World Population Conference, E/CONF.60/SYM. $111 / 7,22$, de agosto de 1973.

$\rightarrow$ K. E. Boulding. "The Economics of the Coming Spaceship Earth", en A. Toffler, op. cit.

La selección más amplia de estas críticas se encuentra en W. L. Oltmans (Comp.), On Growth, Nueva York, G. P. Putnam's Sons, 1974.

"Consúltense al respecto los trabajos de Rosenstein-Rodan y de Weisskopf en J. N. Bhagwati (Comp.), Economics and World Order, Nueva York, Mac Millan, 1972 (hay traducción al español, por Ed. Siglo XXI).

${ }^{77}$ Por ejemplo, M. Mesarovic-E. Pestel, La humanidad en la encrucijada, México, Fondo de Cultura Económica, 1975, y S. H. Mendlovitz, On the Creation of a Just World Order, Nueva York. The Free Press, 1975. 
be ocuparse. Es obvio que la interdependencia creciente de sociedades y mercados pone en entredicho los conceptos tradicionales - $y$ acaso ingenuos- de soberanía nacional. Las aflicciones de un país (recesión, violencia, sequías, golpes de estado) involucran a otros, en mayor o menor medida. De aquí que las soluciones - y no sólo los problemas- deben ser ponderados con puntos de mira amplios, incluyendo por supuesto la dimensión temporal.

En otras palabras, la superación eventual de las disparidades entre países habrá de entrañar una significativa reasignación de recursos en el plano internacional acompañada del perfeccionamiento de los sistemas de cooperación. Esto no puede diseñarse -y mucho menos obtenerse- en un período breve. Involucra nuevas fórmulas de negociación, organización y asistencia, y acaso la ruptura del presente orden mundial. De aquí que el tema de la desigualdad no pueda ser eludido por la prospectiva.

\section{c) La reestructuración del sistema internacional}

Este asunto tiene puntos de enlace con el anterior; en cierta medida es la derivación política de una comprobada situación de desigualdad. Pero en las últimas fechas se han hecho señalamientos específicos sobre la eventual remodelación del conjunto internacional; $; *$ de manera que conviene distanciar un tema del otro.

El telón de fondo de estas aspiraciones fue tejido por algunas tendencias de la economía mundial de posguerra al tiempo que ciertos componentes de la presente coyuntura actuaron como catalizadores. Entre las primeras cabe señalar la expansión dinámica del comercio internacional:"! cuyos frutos se distribuyeron desigualmente entre los países; el aceleramiento del proceso de descolonización; el florecimiento de Europa y del Japón y el peso creciente de las economías socialistas, y, en fin, la transferencia significativa de fondos públicos hacia países de incipiente desarrollo, hecho que aparejó consecuencias contradictorias. Por otra parte, la "guerra fría" probablemente facilitó - acaso sin proponérselo- la toma de conciencia de los países de menor ingreso.

En cuanto a los factores coyunturales cabe apuntar: la doble crisis del petróleo y alimentos y sus múltiples ramificaciones; las tendencias recesivas en los grandes centros industriales; el empeoramiento de la relación de precios del intercambio y de la deuda externa en los países de redu-

* Por ejemplo, las resoluciones 3201 (S-VI) y 3202 (S-VI) aprobadas por la Asamblea General de las Naciones Unidas, y la Carta de Derechos y Deberes Económicos de los Estados, aprobada por este organismo en diciembre de 1974 Puntos de vista diferentes a los de estos documentos se encóntrarán en $\mathbf{R}$. W. Tucker, "A New International Order?", Comentary, febrero de 1975, y en el ensayo de D. P. Moynihan citado en la nota 13.

Al respecto véase CEPAL, Estudio Económico de América Latina, 197I, E/CN.12/935/Rev. 1, agosto de 1972. 
cido ingreso, y las insuficiencias marcadas de la urdimbre institucional (Naciones Unidas y agencias especializadas, Fondo Monetario y otros organismos) establecida al término de la guerra.

Estos elementos alteran apreciablemente la constelación internacional e inducen a la revisión de los ordenamientos posbélicos. Fenómenos complejos que hacen imperativa la necesidad de disponer de previsiones sensatas y de rumbos alternativos de acción. Son materia, en suma de exploraciones prospectivas que pretenden elucidar los problemas en un marco comprensivo.

\section{d) La transmutación de los valores}

Es éste un tema preferido de la prospectiva. ${ }^{30} \mathrm{~A}$ primera vista, parece más justo hablar de homogeneización que de transmutación de valores. En efecto, los principales movimientos de la cultura occidental (judaísmo, helenismo, cristianismo, reforma, marxismo y nacionalismos) en unión de alteraciones estructurales de carácter desigual (por ejemplo, la revolución agrícola e industrial, el acoplamiento de la ciencia con la tecnología, las migraciones, etc. han difundido un conjunto de valores tolerado cuando no compartido por buen número de países. Se estaría así más cerca de una "cultura mundial" que de un "gobierno mundial". ${ }^{31}$

Pero una mirada más profunda de la cuestión lleva a algunas reservas. Adviértese, primero, que importantes fracciones de la comunidad humana están totalmente marginados de lo que sin precisión se llama la cultura occidental. Segundo, la internalización de los valores ha sido fragmentaria y contradictoria aún entre aquellos que dicen pertenecer a dicha cultura. Tercero, tanto el progreso industrial como el subdesarrollo multiplican las fuentes de disenso, independientemente de las regimentaciones informales y burocráticas que se imponen en uno y en otro caso. Cuarto -y aquí ya nos acercamos a la preocupación prospectiva- las alteraciones estructurales previsibles (por ejemplo, en el régimen de propiedad, en los usos del tiempo libre, en las modalidades de transporte, en la unidad familiar) aparejarán necesariamente cambios en ideologías y valores.

En este contexto adquieren significado un conjunto de preguntas que merecen sustantiva atención. ${ }^{32}$ ¿Perderá fuerza el consumismo?, ¿dónde y entre quiénes?, ¿se multiplicarán los "miedos a la libertad"), ¿se agrietarán los fundamentos metropolitanos de la cultura?, ¿se difundirán modalidades fundamentalistas de acción (misticismo, escatologías, nativis-

${ }^{30}$ Véase, por ejemplo, K. Baier - N. Resher (Comp.), Values and The Future, Homewood, Ill., The Free Press, 1969.

${ }^{31}$ Según Ali A. Mazrui, World Culture and the Searah for Human Consensus, Kampala, Makarere University, 1973.

${ }_{3 a}$ No todos los modelos han procedido así. Suponer la inmutabilidad de los valores es una de las flaquezas - sin ignorar los méritos- de los dos ejercicios del Club de Roma. Véase nuestra crítica en Comercio Exterior, julio de 1975, pp. 807-809. 
mo)?, ¿cuáles serán "las preferencias de los consumidores" - -si tendrán alternativas - en un contexto de "equilibrio global", de "crecimiento cero", o de "confrontación darwiniana"?

\section{Gravitación DEL SUBDESARROLlo}

Al vincular las consideraciones hechas en este ensayo con la situación del subdesarrollo que peculiariza a los países latinoamericanos enfrentamos una paradoja: si se tienen presentes las áreas temáticas abordadas por importantes corrientes de la prospectiva, el interés de los países subdesarrollados por ésta debería ser incomprimible. Pero no es así. En estos países apenas se presentan las condiciones -institucionales y actitudinales- que podrían promover los estudios de prospectiva.

Esto no quiere decir que en algunos países de la región (por ejemplo, México, Venezuela, Brasil, Argentina) no se vislumbren inquietudes e iniciativas en este campo. Hasta se habla de un Modelo Latinoamericano. ${ }^{33}$ Pero las dificultades son múltiples.

La paradoja invita a la reflexión: ¿cuáles son los obstáculos que entorpecen la exploración prospectiva en países como los latinoamericanos?, ¿qué puede resultar del descuido de la misma?, ¿pueden algunos países -o en su defecto algún mecanismo regional- superar aquellos obstáculos?

El análisis que sigue hará hincapié en las primeras dos preguntas, con algunas referencias a la última. Advirétase que la cuestión de los obstáculos no puede resolverse en términos psicologistas ("la indiferencia o la torcida voluntad de los burócratas"), tampoco cabe inculpar a la "potencia hegemónica", aunque circunstancias de uno u otro tipo pueden tener peso en casos concretos. Nuestra tesis - como se verá- es más bien estructuralista. Por otra parte, de momento no se pretende alcanzar una interpretación satisfactoria del fenómeno; sólo se presentarán algunos señalamientos que una investigación documental y empírica más amplia deberá enriquecer o rechazar. Se reconoce, por último, la diversidad de situaciones nacionales que se revela en la región, hecho que limita el valor de las generalizaciones que suelen proponerse.

Con estas advertencias retomemos el hilo.

En la primera sección de este ensayo expusimos algunos determinantes de la reflexión prospectiva. Pocos negarán que las sociedades latinoamericanas exhiben mayores grados de complejidad, interdependencia y disenso que en otros tiempos. No hay necesidad de apelar a esquemas conceptuales generales - "capitalismo dependiente", "modernización económica", "evolución desequilibrada"- para aceptar que factores como la industrialización, las migraciones, los medios de comunicación de masas y la

3éanse anticipos en Latin American World Model, Buenos Aires, Fundación Bariloche, octubre 1973. 
movilización política han alterado la fisonomía de la región. ${ }^{34}$ Pero si en el contexto de las sociedades industriales los tres factores mencionados (complejidad, interdependencia y disenso) han facilitado el desenvolvimiento de los estudios de prospectiva, no es éste el caso en América Latina. La explicación parece estribar en varias circunstancias, de las cuales tres merecen especial atención: $i$ ) la índole de la información; ii) las modalidades de decisión; iii) las presiones de corto plazo.

i) El problema de la información. Ya se ha visto que la prospectiva se apoya principalmente en un tipo particular de conocimiento ("tácito", "no factual") al comprobar las insuficiencias de las extrapolaciones. Pero el presente le brinda, de todos modos, un juego de datos confiable que ordena el ejercicio imaginativo. Pero en América Latina contamos con una información que es doblemente tácita. Sin llegar a decir que aquí pasado, presente y futuro son cuasi-invenciones interesadas, puede apuntarse el carácter fragmentario - preliminar en todo caso- de la historiografía, ${ }^{37}$ de la investigación socioeconómica y de los estudios de coyuntura. Las flaquezas de la información son conocidas por cualquier analista serio de la problemática latinoamericana. ${ }^{3 i}$ Difícilmente se podría hacer prospectiva con base en un desconocimiento al cuadrado.

El problema podría superarse, sin embargo, y, de hecho, viene mejorando el estado de la información. Pero hay otros dos factores macrosociales que complican el asunto.

ii) Las modalidades de decisión. A la prospectiva interesa la colección de hipótesis y el esbozo de situaciones probables ("escenarios") en cuanto trasfondo y marco de decisiones que deben asumirse en un presente determinado. Pero ¿a quién concierne esa función cuando los mecanismos decisionales son inestables, contradictorios e ineficientes? Usando los términos acuñados por Hirschman: la prospectiva actúa como voice que tiende a atrofiarse en cuanto los dispositivos de decisión fomentan el exit.3i

En otras palabras, en buen número de países latinoamericanos el Estado (la polity sería un concepto más preciso) apenas ha podido institucionalizar los mecanismos de decisión; por erráticos y desordenados tienden a

:" Indicadores al respecto véanse en la CEPAL. Cambio social y descrrollo social en Latinoamérica. E/CN.12/826, abril de 1969. y en la CEPAL. El desarrollo latinoamericano y la coyuntura económica internacional. E/CEPAL/981, 21 de febrero, 1975

La historiografía pretende no sólo el conocimiento ordenado del pasado; documenta también el presente. Nueva corroboración de este asunto puede encontrarse en I. Wallerstein, The Modom World System. Nueva York, Academic Press, 1974. especialmente pp. 9 ss.

:it No se desprecian los progresos que se han alcanzado en algunos campos (demografía, transacciones externas, por ejemplo) e instituciones (CLADES). Tampoco se ignora que algunos profesionales pretextan su mediana productividad haciendo relucir las debilidades de la información.

:77 A. O. Hirschman, Exit, Voice and Loyalty, Cambridge, Mass. Harvard University Press, 1970, pp. $30 \mathrm{ss}$. Es lamentable que este jugoso libro no haya despertado el interés que en verdad merece. 
postergar $^{38}$ la solución de problemas. En estas circunstancias, la demanda social de estudios de prospectiva despunta tímidamente.

iii) Las presiones de corto plazo. Todo sistema socioeconómico es agredido por presiones inmediatas. Mas se producen diferencias de, grado que son significativas. En los países industriales se han apoyado instituciones que pretenden aislarse de las presiones inmediatas a fin de cumplir funciones sociales reconocidas. Piénsese en algunos centros universistarios, institutos independientes, y hasta dependencias gubernamentales. No así en la región, en donde se observa una politización total - con diferencias de matiz- del aparato estatal, de las universidades, y del sector privado. Esta áspera lucha, bien por la asignación de recursos, bien por la sobrevivencia social y hasta física, mutila cualquier intento de encapsulamiento. El hecho tiene dos consecuencias. Por un lado, desalienta cualquier inclinación a una modalidad reflexiva que procure desconectarses analíticamente del presente; por otro, se precipitan soluciones de corto aliento que abren el paso a problemas aún más graves. Trátase de una infortunada situación de origen muy complejo. Agrieta, en cualquier caso, la aptitud previsora de la región.

Veamos ahora los obstáculos político-organizacionales: a) las debilidades de la planificación; $b$ ) el escaso número de corporaciones multinacionales latinoamericanas; $c$ ) el estilo de la politización externa.

\section{a) Las debilidades de la planificación}

Se ha sugerido en la primera parte del ensayo que los ejercicios de planificación y programación han tenido un efecto saludable en la prospectiva. De aquí la siguiente tesis: cuando la experiencia planificadora es reducida, errática o contradictoria los estudios de prospectiva carecen de puntos conceptuales y operativos de referencia. Con salvedades, éste sería el caso de la región.

La primera parte de la tesis se apoya en amplios recuentos que se han efectuado en torno a las condiciones, el desenvolvimiento y los logros de la planificación en América Latina. ${ }^{39}$ Huelga reiterarlos. A la segunda ya se ha aludido. Sólo cabe agregar que la planificación como ejercicio sostenido de acción pública auxilia a la prospectiva en la medida en que: 1) sensibiliza las decisiones con respecto a la variable tiempo; 2) le reconoce un estatus organizativo autónomo, considerando que la función de la prospectiva es crear marcos de referencia para las decisiones que no el compromiso con éstas.

$\approx$ La postergación de soluciones se hace no sólo en términos explícitos. Nos son familiares las "reorganizaciones" y "las solicitudes de estudios" como expedientes dilatorios. Por supuesto, hay también reorganizaciones y solicitudes necesarias y legítimas.

R. Cibotti-E. Sierra, El sector público en la planificación del desarrollo, México, Siglo XXI, 1970, y R. Cibotti-J. Bardeci, Un enfoque crítico de la planificación en América Latina, Santiago de Chile, ILPES, julio de 1972. 


\section{b) El número reducido de corpóraciones latinoamericanas}

El tema tiene, desde luego, varios aspectos. Aquí inetresa este señalamiento: las corporaciones representan una de las manifestaciones más salientes de la racionalización burocrática; tienden, por lo tanto, a minimizar incertidumbres por medio de una capacidad amplia de previsión y control. Es más: al actuar por encima del horizonte temporal de los estados nacionales, estas entidades tienen una visión comprensiva de las variables ambientales y económicas que pueden afectar a sus intereses. Se sigue de estas premisas que la falta o insuficiencia de corporaciones multinacionales latinoamericanas tiene efectos adversos en la reflexión prospectiva. ${ }^{40}$

\section{c) El estilo de la politización externa}

Ya se ha expuesto que el presente panorama internacional encierra un juego de amenazas y contramenazas que reviste dos características significativas: 1) comprende prácticamente todas las facetas del relacio-namiento internacional; 2) es profundamente afectado por el progreso tecnológico. Y ya hemos visto que esta situación ha propiciado las indagaciones más o menos disciplinadas del futuro. No así en los países de reducido ingreso, que si bien han transitado de una etapa de pasividad (hasta los sesentas) a otra de activa protesta, no han alterado sustancialmente sus marcos conceptuales de referencia. A lo sumo se advierte la simplificada aplicación de ciertas categorías marxistas al régimen internacional.

Dicho de otra manera, las naciones económicamente menos avanzadas - las latinoamericanas entre ellas - tienden a externalizar gestos de denuncia respecto al sistema de estratificación mundial, particularmente en materias tales como la transferencia de recursos, el comercio de productos básicos, y la reforma de los organismos de cooperación. Pero esta externalización tiene de momento efectos limitados. Primero, porque el marco conceptual dominante en estos países no tiene presentes las incidencias de la revolución científico-tecnológica contemporánea ni los resultados contradictorios de la multipolaridad; a lo sumo produce una retórica desmesurada que podría entrañar la autoderrota de las mejores causas de los países de reducido ingreso. ${ }^{41}$ Segundo, porque no se han promovido innovaciones institucionales internas en correspondencia a las nuevas actitudes que se declara asumir en la negociación internacional. Por ejemplo, en muy pocos de los países latinoamericanos se ha ensayado crear un amplio centro de estudios norteamericanos o soviéticos, que confiera bases intelectuales firmes a lo que ideológicamente se declara

to No sólo en ella, por supuesto.

"Sobre este peligro véase V. L. Urquidi, "Problemas globales y tercer mundismo en Guanajuato", Plural, Núm. 48, septiembre, México, 1975. 
en torno a "la potencia hegemónica", "los mecanismos de expoliación", y la confrontación entre "los centros y las periferias". Finalmente, porque la denuncia del orden internacional vigente no ha sido acompañada, en la generalidad de los casos, por transformaciones de envergadura en el interior de los países en desarrollo. Al contrario, se aplican en muchos de ellos - y sin protocolo alguno- medidas represivas que sustraen legitimidad intelectual a la externalización. ${ }^{42}$

Como quiera que sea, la situación descrita -en unión de otros factores - no estimula el anticipo ordenado de tendencias y escenarios. Este requiere componentes intelectuales e institucionales que el dominante estilo de externalización apenas puede suministrar.

Consideremos, finalmente, los obstáculos que se derivan de la diferenciación profesional y de la desideologización, o mejor dicho, del restringido grado de ambas.

1) Institucionalización fragmentaria del rol profesional. Hay bases para suponer que en economías de menor desarrollo no se verifican procesos de diferenciación profesional y disciplinaria similares a los que exhiben las sociedades industriales. Es más, el rol "hombre de ciencia" apenas llega a institucionalizarse ${ }^{43}$ en disciplinas ya consideradas como tales en las postrimerías del siglo xIX. El limitado progreso de la reflexión prospectiva representaría, desde este ángulo, el resultado natural de esta fragmentaria diferenciación. Por supuesto, si éste fuera el único obstáculo podría plantearse la posibilidad de "saltar etapas" en los procesos de institucionalización de las disciplinas. Pero el asunto es, sin duda, más complejo.

2) Resistencias a la desideologización. Ya hemos visto que un lenguaje explícito, coherente y controlado es particularmente requerido por la exploración prospectiva. No es el único requisito, ni éste -conviene insistir - contradice "los compromisos sociales" del investigador. Pero sucede que en economías subdesarrolladas — por factores complejos que huelga comentar aquí- - se gestan resistencias a una desideologización selectiva. Más aún, las confrontaciones internas, la inestabilidad de hombres e instituciones, y el pausado cambio estructural propician una penetrante ideologización de los problemas colectivos. Para ciertos propósitos —por ejemplo, la lucha por el poder - el fenómeno puede ser útil y comprensible; desde otro punto de mira, entorpece la percepción ordenada de cuestiones que habrán de gravitar, acaso independientemente de la suerte de esa lucha interna. ${ }^{4+}$

1: El término alude al complejo de actitudes respecto a los centros influyentes y, en general, al sistema internacional. Véase al respecto $\mathrm{Ph}$. Schmitter, "Contradicciones y crisis en la integración centroamericana", Revista de la integración, noviembre de 1969

1:3 La institucionalización denota, entre otros casos, firme aceptabilidad social y académica. Acerca de este proceso véase J. Ben David, El papel de los cientificos en la sociedad, México, Ed. Trillas, 1974, y M. Crossland, "The Development of a Professional Career in Scienc in France", Minerva, Vol. XIII, Núm. 1, primavera de 1975.

"Esta afirmación tiene sólo valor relativo. Es claro que una confrontación interna 
Examinados algunos de los obstáculos que dificultan el avance de la reflexión prospectiva en paíse subdesarrollados —en América Latina en particular- conviene hacer algunos señalamientos sobre el daño social que esta situación puede entrañar. Es claro que si concebimos la prospectiva como una innocua frivolidad intelectual que algunos países sobrados de riqueza se permiten, mal puede hablarse de "daño social". Pero se trata de demostrar en este ensayo que la imaginación de futuros no es intrascendente; legítima y afecta decisiones que tienen amplia repercusión en los patrones de convivencia humana.

El descuido de la prospectiva tiene varios efectos; interesa aquí hacer hincapié en tres de ellos.

El efecto sorpresa. La ausencia o debilidad de la capacidad de previsión hace que los círculos responsables de un país sean constantemente sorprendidos por el giro de acontecimientos significativos. Van a remolque de los mismos, presumiblemente ocupados en problemas colectivos apremiantes. Pero esta imprevisión limita objetivamente la aptitud para el diagnóstico y la formulación de políticas. Las justas reclamaciones de algunos analistas en el sentido de que "los problemas del subdesarrollo deben ser contemplados en una dimensión histórica" no han sido complementadas por un llamado a la "visión prospectiva del subdesarrollo". Paradójicamente, ensayos en esta dirección se han efectuado relativamente más en los países industriales que en los subdesarrollados. ${ }^{45}$

El efecto sorpresa tiene una expresión sutil: debido a la complejidad de los fenómenos sociales y de las interdependencias que les son inherentes se precisan modalidades de acción contraintuitivas, sensibles a las consecuencias mediatas (de segundo y tercer orden) de una decisión. ${ }^{46} \mathrm{De}$ aquí que la puesta en marcha de políticas divorciadas de una visión sistémica y de largo plazo puede tener resultados contraproducentes, que no fueron buscados por el formulador de las mismas.

El efecto segregación. La insensibilidad a las tendencias de largo plazo habrá de acentuar la marginalidad científica de los países subdesarrollados. Existen indicaciones de que ésta ya es considerable. Por ejemplo, la participación de América Latina en globo en el "producto científico mundial" - teniendo presentes su población e ingreso- es relativamente inferior a la de países como Suiza, Israel o la India. ${ }^{47}$ La carencia de previsiones sobre la marcha futura de ciertas disciplinas y áreas, así como de

que culmina, bien con un nuevo orden más viable que el precedente, bien con la destrucción del acervo de recursos que el pais apenas había podido acumular, altera el diseño de los futuros probables y posibles.

4: Al respecto véase - aparte de la literatura citada_- P. Massé (Comp.), El tercer mundo en el 2000. México, Ed. Diana, 1973.

t" Según J. W. Forrester, "Counterinteritive Behavior of Social Systems", en D. L. Meadows-D. H. Meadows (Comps.), Toward Global Equilibrium, Cambridge, Mass.. Wright-Allen Press, 1973.

* Véanse los datos que presenta P. González Blasco. "La producción científica española de 1965 a 1970: un estudio comparado". Revista Mexicana de Sociología. enero-marzo de 1975. 
los mecanismos institucionales que estimulan la acumulación científica. podría tornar irreversible el atraso científico de la región.

El efecto sobre-reacción/apatia. Imprevisión y marginalidad producen a su vez un encadenamiento de efectos negativos. Uno de ellos es la tendencia a adoptar comportamientos públicos desordenados ("anomia", en el lenguaje de los sociólogos) que tienen expresiones desproporcionalmente agresivas en algunos casos, y de injustificada indiferencia, en otros. En este sentido la indagación prospectiva acaso podría contribuir a moderar estas desviaciones.

\section{Algunos prerrequisitos de la especulación prospectiva}

Si aceptamos que la indiferencia a las especulaciones de largo plazo involucran daños sociales de orden desigual, cabe preguntar: ¿cuáles "son los prerrequisitos del ejercicio prospectivo que los países subdesarrollados -especialmente América Latina- deberían satisfacer?

\section{a) Apoyo institucional}

Trátase de la asignación adecuada de recursos y del ofrecimiento de servicios de apoyo sin firmes ataduras a los vaivenes de la coyuntura política y económica interna. La promoción de fundaciones que apoyen esta actividad, en unión de los centros académicos, podría representar un paso en esta dirección.

\section{b) Libertad intelectual}

Es condición, por supuesto, de cualquier disciplina, y más aún de este quehacer crítico y "subversivo" que es la prospectiva. Porque especulaciones sobre el futuro suelen traducirse en inconformidad con el presente o, por lo menos, en la percepción aguda de sus limitaciones.

\section{c) Selectividad}

Ciertamente, no se pueden explorar simultáneamente todas las áreas temáticas que parecen de interés desde algún ángulo. No es una orgía de previsiones lo que se debe buscar, sino el encuadramiento de problemas seleccionados, en un horizonte de largo plazo. Se deberá minimizar el peso de elecciones gratuitas. 


\section{d) Flexibilidad}

Principalmente en el terreno metodológico habrá necesidad de innovar, por cuanto las técnicas en boga (escenarios, consultas délficas, cuadros de impactos cruzados, combinaciones probabilísticas) suponen la existencia previa de una infraestructura mínima en términos de informática, recursos humanos y de capital, infraestructura que es débil y fragmentaria en economías de menor ingreso.

$\mathrm{Si}$ se contrastan estos prerrequisitos -y la lista no es exhaustivacon las rigideces institucionales y financieras que se advierten, por ejemplo, en la mayoría de los países latinoamericanos, difícilmente podrían albergarse expectativas sobre el futuro de la prospectiva en la región... Acaso las economías de mayor tamaño relativo podrían permitirse el fomento de esta disciplina. En cualquier caso, se justificaría el establecimiento de un mecanismo regional de cooperación que alentara los estudios de largo plazo, teniendo presentes los problemas del área. Debería ser un mecanismo singular, razonablemente libre tanto de las rigideces anotadas como de las normas de autocensura que algunos organismos internacionales suelen explícita o implícitamente instituir. 